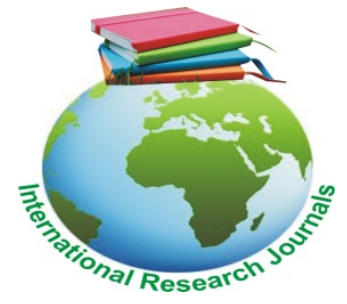

\title{
Reproductive health knowledge and sexual behaviours of adolescents with learning disabilities in Ibadan North local government area, Oyo State
}

\author{
Ademokoya J.A and Igbeneghu P.E \\ Department of Special Education University of Ibadan, Ibadan \\ Corresponding author's email: patienceigbeneghu@gmail.com
}

\begin{abstract}
Adolescents with learning disabilities (ALDs) are prone to various challenges of reproductive health. These challenges are similar to what their regular counterparts do experience. It is unfortunate that as a minority, ALDs' challenges hardly receive attention of researchers and intervention providers. As a result, unwanted pregnancies, sexually transmitted infections and sexual abuses usually leave more prolonged and serious consequences on them than those experienced by their regular counterparts. This study therefore attempted to explore knowledge and sexual behaviours of ALDs in a Nigerian city. Descriptive survey design was adopted for the study. A purposive sampling technique was used to select 210 adolescents with learning disabilities in Ibadan North Local Government Area (LGA) of Oyo State, Nigeria (105 males, 105 females). Two research instruments were used; namely The Pupil Rating Scale ( $r=0.62)$ used in screening for learning disabilities and an Adolescent with Learning Disabilities' Reproductive and Sexual Behaviour Inventory $(r=0.89)$. Four research questions were postulated, descriptive statistics and simple percentages were used for the data analysis. Findings showed that among ALDs, the most common source of information on reproductive and sexual behaviour was mass media (29.0\%), and the age for experiencing first sexual intercourse was highest at early adolescents (11.9\%), followed by the middle adolescents (9.0\%) and then the late adolescents $(4.3 \%)$. The general knowledge on reproductive health was high among ALDs (86.7\%), though access to reproductive health facilities was low, as $\mathbf{5 2 . 9 \%}$ had never visited any reproductive health facility, $\mathbf{2 1 . 0 \%}$ had had sexual intercourse and also $23.3 \%$ had been sexually abused. Consequently, the study recommended that sexuality education should be introduced and intensified in the various schools, particularly, the early ALDs to minimise the incidence of sexual abuse, unwanted pregnancies and STIs. Further,, mass media should serve in disseminating information on sexuality to ALDs.
\end{abstract}

Keywords: Reproductive health, sexual behaviour, adolescents, learning disabilities.

\section{INTRODUCTION}

Adolescents with learning disabilities (ALDs) are often bright, creative and capable, but have neurological or behavioural/emotional issues that impact their performance in certain areas, such as reading, mathematics and social skills. They might perform exceptionally well in one area but underachieve in another. Because they have experienced many years of failure, they begin to doubt their intellectual abilities, lack resiliency and come to believe that their efforts to achieve is futile. They in-turn display low persistence level; give up as soon as something appears to be difficult. ALDs however, have difficulties in problem-solving, also called high-order processing which began in elementary school, when a child experiences difficulties with tasks such as 
word recognition, spelling, computation, these become generalised as a child ages (Swanson, 2008).

ALDs have low academic achievement, which can have a negative impact on how they feel about school and themselves. It is estimated that one million adolescents affected by learning disabilities in United States of America drop out of high school each year and within three to five years of dropping out, $50 \%$ of females with learning disabilities are pregnant (Sexuality Issues for Youth with Disabilities and Chronic Health Conditions, 2008). Reproductive health as defined by the World Health Organisation (WHO) is a state of physical, mental and social well-being in all matters relating to the reproductive system at all stages of life. Reproductive health implies that people are able to have satisfying safe sex life, with the capacity to reproduce as well as the freedom to decide if, when and how often to do so. Implicit in this are the right of males and females including adolescents with learning disabilities to have access to appropriate health care services of sexual and reproductive medicine that will enable women safely go through pregnancy and childbirth (WHO, 2008).

Learning about sexual behaviour is a lifelong and often haphazard process. Babies learn from birth onwards about the bodily pleasure of being warm, cuddled, tickled and interacted with. Others learn from watching the ways in which parents show affection to each other and from spoken and unspoken messages about private parts; also from films, advertisements and soap operas on television. Sadly, it is often the case that ALDs only get a very negative form of sex education. Not giving them any positive formal or sensible sex education does not mean that they do not pick up many enticing ideas. They need to be protected from people who seek them out to exploit their ingenuity (Outsiders, 2009).

An ALD has more difficulty in understanding and communicating, concomitant with increased level of vulnerability. As they are unable to understand tasks as well as other normal children of the same age they are often brought up with low self-esteem as their caregivers perform more of the task for them than they would for other children. This also leads to more vulnerability and increased risk of sexual abuse than what is seen in children of the same age and normal development (Public Health Agency, 2005). ALDs are therefore at increased risk of sexual and physical abuse and neglect. ALDs will almost certainly show gaps in knowledge and erroneous beliefs when compared with more able peers of the same age, and the degree of these problems will correspond to the extent and nature of their learning disability. They will also reflect the child's history of exposure to comprehensible family and school-based education about personal relationships, privacy, safe touching, sexual expression, dating as well as choosing partners. These gaps in knowledge and understanding will probably reflect the general belief that ALDs are best excluded from sexual education and expression, lest they get into trouble or pose a danger to themselves or others (Allington-Smith, Ball and Haytor, 2002).

There are a number of wider factors which may impact on the sexual behaviour of ALDs and the likelihood of such behaviour resulting in a referral to specialist services. Some of these are:

- ALDs are more likely than those without learning difficulties to have experienced abuse of all kinds (Sullivan and Knutson, 2000; NSPCC, 2003) and disability is also associated with longer durations of abuse. Whilst there is no direct or linear relationship between experiencing childhood abuse and going on to perpetrate acts of sexual abuse (Freidrich, 1998), high levels of abuse are noted in almost all samples of sexual abusers.

- The sex education available to ALDs may be limited and insufficient (Hackett, 2004). Even when high quality sex education is provided by schools, the nature of ALDs may mean that it is difficult for such adolescents to translate concepts which they have been taught in a classroom into their everyday behaviours - particularly in situations where they may be sexually aroused.

\section{Statement of the Problem}

Knowledge on reproductive health and sexual behaviour among ALDs is generally inadequate. Although some adolescents with learning disabilities are aware of sexual issues, it has been observed that adolescent-friendly health care facilities are not easily available in Nigeria. Moreover, ALDs tend to avoid consulting proper health care providers for reproductive health information. They face a wide variety of reproductive health problems such as unwanted pregnancy, STIs, including HIV due to lack of access to accurate information.

More so, some identified limits to reproductive health and sexual behaviour among adolescents in developing countries like Nigeria include lack of knowledge, poor sex education and access to services; inappropriate risk perception; and negative social norms about premarital sexual activity and pregnancy. These problems have contributed to the increase in unwanted pregnancies, sexual abuses and HIVIAIDs among ALDs.

\section{Research Questions}

1. What is the level of reproductive health awareness among ALDs?

2. What are the main sources of information on reproductive health knowledge and sexual behaviour available to ALDs? 
3. At what age is first sexual intercourse prominent among adolescents with learning disabilities?

4. What are sexual behaviour trends among ALDs?

\section{Purpose of the Study}

The main purpose of this study is to investigate the reproductive health knowledge and sexual behaviours among ALDs. The objectives of this study are to:

1. Ascertain the level of reproductive health knowledge among ALDs

2. Identify sexual behaviours of ALDs

3. Proffer some solutions to the problems of ALDs on their reproductive health and sexual behaviours problems.

\section{Significance of the Study}

The study focused on ALDs because they are perhaps vulnerable groups to sexual abuses, an important group in a society and also a country's valuable future assets.

This study should be of benefit to special educators, schools, teachers, counselling psychologists, educational planners and society at large in identifying the reproductive health needs and sexual behaviours of ALDs.

Also, this study is expected to proffer recommendations on how the incidence of sexual abuses, risky sexual behaviours, unwanted pregnancies, sexually transmitted infections (STIS) and HIVIAIDS can be reduced among ALDs.

\section{METHODOLOGY}

This study adopted a descriptive survey design to investigate reproductive health knowledge and sexual behaviours among ALDs in Ibadan North LGA of Oyo State. A simple random sampling was employed to select seven public secondary schools in Ibadan North LGA of Oyo State. In each of the selected schools, class teachers nominated adolescents with record of poor academic performance based on their past examination records. After which there was a further screening of the selected students for learning disabilities using Pupils Rating Scale. Finally, 30 students identified as having learning disabilities from each of the selected schools making a total of 210 participants were used in the study.

Two research instruments were used for this study; namely The Pupil Rating Scale (Myklebust, 1981) Revised with reliability coefficient of 0.62 (Lazarus, 2009) and Adolescents with Learning Disabilities' Reproductive and Sexual Behaviour Inventory, with a reliability coefficient of 0.89 .

\section{Data Analysis}

Data collected for the study was analysed through a qualitative scale, whereby alternate responses were allotted to the items in the Adolescents with Learning Disabilities' Reproductive and Sexual Behaviour Inventory in order to make it uniform in decision-making. Frequencies and percentages were used generally for the research questions.

\section{RESULTS}

Research Question 1: What is the level of reproductive health awareness among ALDs?

The responses in Table 1 show that $86.7 \%$ (41.0\% male and $45.7 \%$ female) agreed they should be informed about male and female reproductive organs. The result indicates that:

$69.5 \%$ (33.3\% males and $36.2 \%$ females) agreed that an adolescent girl could get pregnant at first sexual intercourse.

$49.0 \%$ (26.2\% males and $22.9 \%$ females) agreed that pregnancy could occur few days before menstruation.

$60.0 \%$ (28.1\% males and $31.9 \%$ f females) responded they felt shy talking about sexual organs of male and female bodies.

$52.9 \%$ (26.7\% males and $26.2 \%$ females) had not visited a health facility for reproductive health services.

$60.5 \%$ (31.0\% males and $29.5 \%$ females) disagreed that their parents had never discussed reproductive health with them

$73.8 \%$ (36.7\% males and $37.1 \%$ females) agreed that sex education could prevent unwanted pregnancy.

$72.4 \%$ (35.7\% males and $36.7 \%$ females) agreed that they did have and read information about reproductive health.

93.3\% (45.2\% males and $48.1 \%$ females) had heard about sexually transmitted diseases and HIVIAIDS.

$81.4 \%$ (40.5\% males and $41.0 \%$ females) agreed that ovulation was the release of mature egg from the ovary.

$93.3 \%$ (44.3\% males and $49.0 \%$ females) agreed that changes in the body did occur during puberty.

\section{Research Question 2: What are the main sources of information on reproductive health knowledge and sexual behaviour available to ALDs?}

Table 2 reveals that $29.0 \%$ of the total participants 
Table 1: Level of Reproductive Health Awareness among Adolescents with Learning Disabilities

\begin{tabular}{|c|c|c|c|c|c|c|c|c|c|c|c|c|c|c|c|c|c|c|}
\hline \multirow{3}{*}{ Knowledge of reproductive health } & \multicolumn{6}{|c|}{ Male } & \multicolumn{6}{|c|}{ Female } & \multicolumn{6}{|c|}{ Total } \\
\hline & \multicolumn{2}{|c|}{ Agree } & \multicolumn{2}{|c|}{ Disagree } & \multicolumn{2}{|c|}{ Undecided } & \multicolumn{2}{|c|}{ Agree } & \multicolumn{2}{|c|}{ Disagree } & \multicolumn{2}{|c|}{ Undecided } & \multicolumn{2}{|c|}{ Agree } & \multicolumn{2}{|c|}{ Disagree } & \multicolumn{2}{|c|}{ Undecided } \\
\hline & No & $\%$ & No & $\%$ & No & $\%$ & No & $\%$ & No & $\%$ & No & $\%$ & No & $\%$ & No & $\%$ & No & $\%$ \\
\hline $\begin{array}{l}\text { An adolescent should be informed } \\
\text { about reproductive health and organs } \\
\text { of the male and female bodies. }\end{array}$ & 86 & 41.0 & 12 & 5.7 & 7 & 3.3 & 96 & 45.7 & 2 & 1.0 & 7 & 3.3 & 182 & 86.7 & 14 & 6.7 & 14 & 6.7 \\
\hline $\begin{array}{l}\text { An adolescent girl can get pregnant at } \\
\text { first sexual intercourse }\end{array}$ & 70 & 33.3 & 16 & 7.6 & 19 & 9.0 & 76 & 36.2 & 15 & 7.1 & 14 & 6.7 & 146 & 69.5 & 31 & 14.8 & 33 & 15.7 \\
\hline $\begin{array}{l}\text { Having sex while standing or sitting } \\
\text { prevents unwanted pregnancy }\end{array}$ & 16 & 7.6 & 74 & 35.2 & 15 & 7.1 & 11 & 5.2 & 70 & 33.3 & 24 & 11.4 & 27 & 12.9 & 144 & 68.6 & 39 & 18.6 \\
\hline $\begin{array}{l}\text { Pregnancy can occur few days before } \\
\text { menstruation/period }\end{array}$ & 55 & 26.2 & 28 & 13.3 & 22 & 10.5 & 48 & 22.9 & 30 & 14.3 & 27 & 12.9 & 103 & 49.0 & 58 & 27.6 & 49 & 23.3 \\
\hline $\begin{array}{l}\text { Pregnancy can occur during } \\
\text { menstruation/period }\end{array}$ & 48 & 22.9 & 36 & 17.1 & 21 & 10.0 & 55 & 26.2 & 27 & 12.9 & 23 & 11.0 & 103 & 49.0 & 63 & 30.0 & 44 & 21.0 \\
\hline $\begin{array}{l}\text { Pregnancy can occur at the end of } \\
\text { menstruation/period }\end{array}$ & 53 & 25.2 & 17 & 8.1 & 35 & 16.7 & 54 & 25.7 & 20 & 9.5 & 31 & 14.8 & 107 & 51.0 & 37 & 17.6 & 66 & 31.4 \\
\hline $\begin{array}{l}\text { I do feel shy to talk about sexual } \\
\text { organs of male and female bodies }\end{array}$ & 59 & 28.1 & 37 & 17.6 & 9 & 4.3 & 67 & 31.9 & 29 & 13.8 & 9 & 4.3 & 126 & 60.0 & 66 & 31.4 & 18 & 8.6 \\
\hline $\begin{array}{l}\text { I do visit a health facility for } \\
\text { reproductive health services }\end{array}$ & 33 & 15.7 & 56 & 26.7 & 16 & 7.6 & 34 & 16.2 & 55 & 26.2 & 16 & 7.6 & 67 & 31.9 & 111 & 52.9 & 32 & 15.2 \\
\hline $\begin{array}{l}\text { My parents have never discussed } \\
\text { reproductive health with me }\end{array}$ & 32 & 15.2 & 65 & 31.0 & 8 & 3.8 & 37 & 17.6 & 62 & 29.5 & 6 & 2.9 & 69 & 32.9 & 127 & 60.5 & 14 & 6.7 \\
\hline $\begin{array}{l}\text { Sex education can prevent unwanted } \\
\text { pregnancy }\end{array}$ & 77 & 36.7 & 23 & 11.0 & 5 & 2.4 & 78 & 37.1 & 26 & 12.4 & 1 & 0.5 & 155 & 73.8 & 49 & 23.3 & 6 & 2.9 \\
\hline $\begin{array}{l}\text { I do have and read information about } \\
\text { reproductive health }\end{array}$ & 75 & 35.7 & 22 & 10.5 & 8 & 3.8 & 77 & 36.7 & 23 & 11.0 & 5 & 2.4 & 152 & 72.4 & 45 & 21.4 & 13 & 6.2 \\
\hline $\begin{array}{l}\text { I have heard about sexually } \\
\text { transmitted diseases (STDs) and } \\
\text { HIVIAIDS }\end{array}$ & 95 & 45.2 & 6 & 2.9 & 4 & 1.9 & 101 & 48.1 & 3 & 1.4 & 1 & 0.5 & 196 & 93.3 & 9 & 4.3 & 5 & 2.4 \\
\hline $\begin{array}{l}\text { Reproductive health services are } \\
\text { important to adolescents with learning } \\
\text { disabilities }\end{array}$ & 74 & 35.2 & 24 & 11.4 & 7 & 3.3 & 81 & 38.6 & 18 & 8.6 & 6 & 2.9 & 155 & 73.8 & 42 & 20.0 & 13 & 6.2 \\
\hline $\begin{array}{l}\text { Ovulation is the release of matured } \\
\text { egg from the ovary }\end{array}$ & 85 & 40.5 & 8 & 3.8 & 12 & 5.7 & 86 & 41.0 & 8 & 3.8 & 11 & 5.2 & 171 & 81.4 & 16 & 7.6 & 23 & 11.0 \\
\hline $\begin{array}{l}\text { Changes in the body do occur during } \\
\text { puberty }\end{array}$ & 93 & 44.3 & 10 & 4.8 & 2 & 1.0 & 103 & 49.0 & 1 & 0.5 & 1 & 0.5 & 196 & 93.3 & 11 & 5.2 & 3 & 1.4 \\
\hline
\end{tabular}


Table 2: Main Sources of Information on Reproductive health and Sexual Behaviour

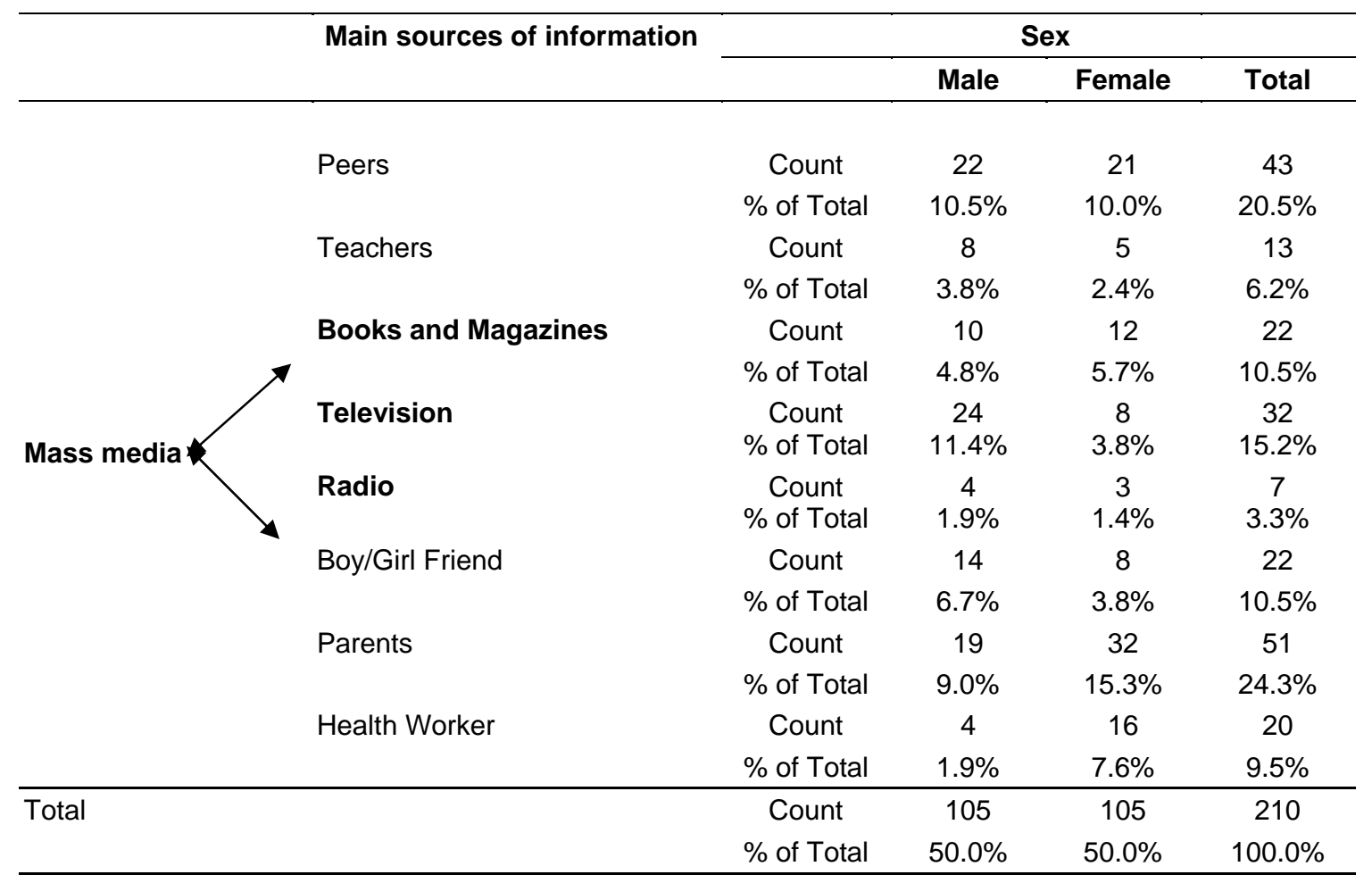

Table 3: Age at first Sexual Experience of Adolescents with Learning Disabilities

\begin{tabular}{lcccc}
\hline Age at first Sexual Experience & \multicolumn{3}{c}{ Sex } \\
& & Male & Female & Total \\
\hline \multirow{2}{*}{$10-13$ years } & Count & 12 & 13 & 25 \\
& \% of Total & $5.7 \%$ & $6.2 \%$ & $11.9 \%$ \\
$14-16$ years & Count & 12 & 7 & 19 \\
& \% of Total & $5.7 \%$ & $3.3 \%$ & $9.0 \%$ \\
17 - 19 years & Count & 2 & 7 & 9 \\
& \% of Total & $1.0 \%$ & $3.3 \%$ & $4.3 \%$ \\
No experience/response & Count & 79 & 78 & 157 \\
& \% of Total & $37.6 \%$ & $37.2 \%$ & $74.8 \%$ \\
\hline Total & Count & $\mathbf{1 0 5}$ & $\mathbf{1 0 5}$ & $\mathbf{2 1 0}$ \\
& \% of Total & $\mathbf{5 0 . 0 \%}$ & $\mathbf{5 0 . 0 \%}$ & $\mathbf{1 0 0 . 0 \%}$ \\
\hline
\end{tabular}

identified mass media (Books and Magazines, as well as Television and Radio) as their main sources of information on reproductive and sexual behaviour, followed by parents $(24.3 \%)$ and peers $(20.5 \%)$.
Research Question 3: At what age is first sexual intercourse prominent among ALDs?

Table 3 above shows the age at which ALDs had 
Table 4: Sexual Behaviour Trends of Adolescents with Learning Disabilities

\begin{tabular}{|c|c|c|c|c|c|c|c|c|c|c|c|c|c|c|c|c|c|c|}
\hline \multirow[t]{3}{*}{ Knowledge of sexual behaviour } & \multicolumn{6}{|c|}{ Male } & \multicolumn{6}{|c|}{ Female } & \multicolumn{6}{|c|}{ Total } \\
\hline & \multicolumn{2}{|c|}{ Agree } & \multicolumn{2}{|c|}{ Disagree } & \multicolumn{2}{|c|}{ Undecided } & \multicolumn{2}{|c|}{ Agree } & \multicolumn{2}{|c|}{ Disagree } & \multicolumn{2}{|c|}{ Undecided } & \multicolumn{2}{|c|}{ Agree } & \multicolumn{2}{|c|}{ Disagree } & \multicolumn{2}{|c|}{ Undecided } \\
\hline & No & $\%$ & No & $\%$ & No & $\%$ & No & $\%$ & No & $\%$ & No & $\%$ & No & $\%$ & No & $\%$ & No & $\%$ \\
\hline I have a girl/boyfriend & 50 & 23.8 & 50 & 23.8 & 5 & 2.4 & 47 & 22.4 & 57 & 27.1 & 1 & 0.5 & 97 & 46.2 & 107 & 51.7 & 6 & 2.9 \\
\hline $\begin{array}{l}\text { I have had sexual experience(s) } \\
\text { before now }\end{array}$ & 24 & 11.4 & 80 & 38.1 & 1 & 0.5 & 20 & 9.5 & 85 & 40.5 & 0 & 0 & 44 & 21.0 & 165 & 78.6 & 1 & 0.5 \\
\hline I have more than one sexual partner & 10 & 4.8 & 91 & 43.3 & 4 & 1.9 & 9 & 4.3 & 89 & 42.4 & 7 & 3.3 & 19 & 9.0 & 180 & 85.7 & 11 & 5.2 \\
\hline I have sex regularly & 9 & 4.3 & 94 & 44.8 & 2 & 1.0 & 10 & 4.8 & 91 & 43.3 & 4 & 1.9 & 19 & 9.0 & 185 & 88.1 & 6 & 2.9 \\
\hline I have been sexually abused before & 9 & 4.3 & 70 & 33.3 & 2 & 1.0 & 40 & 19.0 & 85 & 40.6 & 4 & 1.9 & 49 & 23.3 & 155 & 73.8 & 6 & 2.9 \\
\hline I have attempted abortion before & 7 & 3.3 & 94 & 44.8 & 4 & 1.9 & 10 & 4.8 & 94 & 44.8 & 1 & 0.5 & 17 & 8.1 & 188 & 89.5 & 5 & 2.4 \\
\hline $\begin{array}{l}\text { It is difficult to obtain information } \\
\text { about sexual behaviour }\end{array}$ & 34 & 16.2 & 59 & 28.1 & 12 & 5.7 & 33 & 15.7 & 64 & 30.5 & 8 & 3.8 & 67 & 31.9 & 123 & 58.6 & 20 & 9.5 \\
\hline $\begin{array}{l}\text { I have visited a health facility to get } \\
\text { sexuality education services }\end{array}$ & 15 & 7.1 & 77 & 36.7 & 13 & 6.2 & 16 & 7.6 & 82 & 39.0 & 7 & 3.3 & 31 & 14.8 & 159 & 75.7 & 20 & 9.5 \\
\hline $\begin{array}{l}\text { Peer pressure has a great influence } \\
\text { on my sexual life }\end{array}$ & 30 & 14.3 & 62 & 29.5 & 13 & 6.2 & 34 & 16.2 & 65 & 31.0 & 6 & 2.9 & 64 & 30.5 & 127 & 60.5 & 19 & 9.0 \\
\hline $\begin{array}{l}\text { I am always attracted to the opposite } \\
\text { sex }\end{array}$ & 32 & 15.2 & 71 & 33.8 & 2 & 1.0 & 21 & 10.0 & 77 & 36.7 & 7 & 3.3 & 53 & 25.2 & 148 & 70.5 & 9 & 4.3 \\
\hline $\begin{array}{l}\text { I have never heard about } \\
\text { homosexuality }\end{array}$ & 23 & 11.0 & 76 & 36.2 & 6 & 2.9 & 23 & 11.0 & 74 & 35.2 & 8 & 3.8 & 46 & 21.9 & 150 & 71.4 & 14 & 6.7 \\
\hline $\begin{array}{l}\text { I believe that masturbation is a kind } \\
\text { of sexual behaviour }\end{array}$ & 42 & 20.0 & 45 & 21.4 & 18 & 8.6 & 49 & 23.3 & 44 & 21.0 & 12 & 5.7 & 91 & 43.3 & 89 & 42.4 & 30 & 14.3 \\
\hline
\end{tabular}

their first sexual experience. $11.9 \%$ (5.7\% males and $6.2 \%$ females) had their first sexual experience between 10 and 13 years.

$9.0 \%$ (5.7\% males and 3.3\% females) had their first sexual experience between 14 and 16 years.4.3\% (1.0\% males and 3.3\% females) had their first sexual experience between 17 and 19 years.
While $74.8 \%$ (37.6\% males and $37.2 \%$ females) had no sexual experience or gave no response.

\section{Research Question 4: What are sexual behaviour trends among ALDs?}

Table 4 shows the responses of the ALDs based on their sexual behaviours.
The result indicates that $46.2 \%(23.8 \%$ males and $22.4 \%$ females) of the respondents had a girl/boyfriend.

$21.0 \%$ (11.4\% males and $9.5 \%$ females) had had sexual experience before now.

9.0\% (4.8\% males and $4.3 \%$ females) had more than one sexual partner while another $9.0 \%$ (4.3\% males and $4.8 \%$ females) had sex regularly 
23.3\% (4.3\% males and $19.0 \%$ females) had been sexually abused while $8.1 \%$ had attempted abortion. $75.7 \%$ (36.7 \% males and 39.0\% females) had never visited a health facility for sex education.

$30.5 \%$ (14.3\% males and $16.2 \%$ females) agreed that peer pressure had more influence on their sexual life.

$71.4 \%$ (36.2\% males and $35.2 \%$ females) disagreed that they had never heard about homosexuality.

\section{DISCUSSION OF FINDINGS}

The study shows that most of the male and female ALDs had general knowledge of reproductive health with $86.7 \%$ of the total population. Despite their knowledge of reproductive health, $60 \%$ of ALD do feel shy to talk about sexual issues while $52.9 \%$ do not visit health facilities for reproductive health services and information. Ejembi and Otu (2004) report that knowledge of most reproductive health among Nigeria students was high.

From the result of the study, it was observed that mass media, parents and peers play important role in the sexuality education of ALDs especially issues relating to reproductive health and sexual behaviours. Similar studies on adolescents without learning disabilities report mass media as the most important source of information on reproductive and sexual behaviour (CSA and ORC Macro, 2006; Tegegn, Yazachew and Gelaw, 2008). In the same vein, Temin, Okonofua, Omorodion, Renne, Coplan, Haggenhougen and Kaufman (1999) state that mass media is the major source of information on sexual behaviour and knowledge about STDs to adolescents, followed by parents and those peers.

The result also reveals that the early adolescence (10 - 13 years) shows higher percentage in their first sexual experience than the middle and late adolescents because it is the period of experimentation for adolescents generally. Corroborating this with adolescents without learning disabilities by Temin et. al. (1999) show that females began having intercourse at a younger age than males; the most commonly stated age of sexual debut for females was between 11 and 13 years compared with between 14 and 15 years for males. Makinwa-Adebusoye (1991), reports that eight per cent of the sexually experienced girls and seven per cent of the sexually experienced boys had their first sexual experience when they were less than 15 years old.

In addition, the study shows that about 21 per cent of ALDs had had sexual intercourse and also, if converted to ratio we will have one in 4.3 ALDs used for this study who indicated having been sexually abused (23.3\%). This supports Sunmola et. al., (2003) that of adolescents without learning disabilities aged 11 to 25 , about $33 \%$ of the population covered had already had first sexual experience but more males than females reported having experience first sexual encounter. This is also in line with the report of Allington-Smith, Ball and Hayfor (2002) that ALDs are susceptible to being sexually abused.

\section{CONCLUSION}

Adolescents with learning disabilities (ALDs) are as sexually experienced as the regular counterpart and they exhibit almost the same pattern of reproductive health and sexual behaviour with those without learning disabilities. Therefore, attitude about sexuality education and counselling needs of ALDs should not be overlooked. Also given that ALDs are susceptible to sexual abuse, this problem should be addressed and not overlooked.

\section{RECOMMENDATIONS}

Premised on this study, the following recommendations are made:

- Sexuality education should be incorporated into the school curriculum for ALDs

- Special educators should be properly placed and be encouraged to help ALDs in solving their sex-related problems.

- Parents should be enlightened, educated and encouraged to be involved in sexuality education of their ALDs at home. Also, the mass media especially should be used in disseminating information on sexuality to ALDs.

\section{REFERENCES}

Allington-Smith P, Ball R, Haytor R (2002). Management of sexually abused children

with learning disabilities. Advances in Psychiatric Treatment, 8: 67-72

CSA,ORC Macro (2006). Ethiopia Demographic and Health Survey. Addis Ababa,

Ethiopia and Calventon, Maryland, USA.

Ejembi CL, Otu A (2004). Sexual behaviour, contraceptive practice and reproductive

health outcomes among Nigerian university students. J. Community Medicine and Primary Health Care, 16(2): 8-16.

Freidrich W (1998). Behavioural manifestations of child sexual abuse. Child Abuse and Neglect, 22: 523-531.

Hackett S (2004). What works for children and young people with harmful sexual behaviours? Ilford: Barnardos.

Lazarus KU (2009). Two instructional strategies as intervention for enhancing reading

comprehension of students with learning disabilities in Lagos state, Nigeria. Unpublished Ph.D thesis. University of Ibadan.

Makinwa-Adebusoye PK (1991). Adolescent reproductive behaviour in Nigeria. A study of five cities. NISER Monograph Series. No. 3 , Ibadan.

Myklebust HR (1981).The Pupil Rating Scale, Revised: Screening for Learning Disabilities. W. B. Saunders Company, New York. 84pages 
NSPCC (2003). It doesn't happen to disabled children. Child protection and disabled children. Report of the National Working Group on Child Protection and Disability. London: NSPCC

Outsiders (2009). Sex and learning disabilities. http//www.outsiders.org.uk/leaflets/pld-Leaflet

Public Health Agency (2005). Abuse of children with disabilities. NCFV Canada

Sexuality Issues for Youth with Disabilities and Chronic Health Conditions (2008). Sexual education for teens with disabilities. http://www.hrtw.org

Sullivan P, Knutson J (2000). Maltreatment and disabilities: a population-based epidemiological study. Child Abuse and Neglect, 24: $1257-1274$

Sunmola AM, Dipeolu M, Babalola S, Adebayo OD (2003). Reproductive knowledge, sexual behaviour and contraceptive use among adolescents in Niger State of Nigeria. African $J$. Reproductive Health, 7(1): 37-48.

Swanson HL (2008). Intervention research for adolescents with learning disabilities. A meta-analysis of outcomes related to high order processing. National Centre for Learning Disabilities. http//www.ncld.org/content/view/523/
Tegegn A, Yazachew M, Gelaw Y (2008). Reproductive health knowledge and attitude among adolescents: a community-based study in Jimma town, Southwest Ethiopia. Ethiopia J. Health Dev., $22(3)$

Temin MJ, Okonofua FE, Omorodion FO, Renne EP, Coplan P, Heggenhougen

HK, Kaufman J (1999). Perceptions of sexual behaviour and knowledge about sexually transmitted diseases among adolescents in Benin City, Nigeria. Int. Family Planning Perspectives, 25(4): 186 - 190 \& 195.

World Health Organization (WHO). 2008. Reproductive Health. http://www.wiawh.org/resourcecenter/informationclearing house/whatisrh.aspx 